\title{
Comparing Robert Noyce Scholars and Non- Robert Noyce Scholars Perceptions of Teaching
}

\author{
Jennifer G. Whitfield ${ }^{\text {a }}$, Hersh Waxman ${ }^{\text {a }}$, \& Timothy Scott ${ }^{\text {a }}$ \\ ${ }^{a}$ Texas A\&M University, USA
}

\begin{abstract}
Staffing high schools with highly qualified math and science teachers continues to be a challenge for school districts across the U.S. (NCTAF, 2010; Ingersoll \& Merril, 2010). One way to address this challenge is to offer financial incentives, in the form of scholarships or grants, for high performing college students to become high school mathematics or science teachers. Oftentimes, attached to these financial incentives are service commitments to which recipients must agree to teach for a specified number of years in a high-need school or district. Investigating the impact these types of scholarship programs have on the high school math and science teacher staffing issue is an area that warrants more research. To help identify some characteristics of students involved in these types of financial incentive programs, our study investigates how the Robert Noyce Scholarship Program influenced students' decisions to become a high school mathematics or science teachers and their dispositions about teaching in schools. In this study, we administered a 70 item survey to 61 participants (29 experimental group, 32 control group) during the summer of 2015. Latent variables were created using Exploratory Factor Analysis and differences between the experimental and control groups were tested with the Mann-Whitney $U$ and Chi-Square tests. Findings indicate statistically significant differences in three areas: (a) scholarship recipients' decisions to become a high school mathematics or science teacher, (b) plans for graduate education, and (c) teacher preparation.
\end{abstract}

Keywords: STEM teacher preparation, Robert Noyce Teaching Scholarship, teaching in high-need schools

\section{Comparing Robert Noyce Scholars and Non-Robert Noyce Scholars Perceptions of Teaching}

The flow of new teachers into classrooms around regions of the U.S. is decreasing and is effecting the stability and sustainability of the teacher workforce. During the 20th century, the supply of teachers generally met the demand. New teachers viewed their job as a lifelong career from which they would retire, and experienced teachers made up the majority of teachers in the profession (Carroll, 2007; Ingersoll \& Merril, 2010). At the end of the 20th century and beginning of the 21 st century, however, the number of experienced teachers in schools decreased (National Commission on Teaching and America's Future [NCTAF], 2010) and new teachers started leaving the profession at detrimentally high rates. Though the estimates for beginning teacher attrition rates vary, it is evident that these rates are high and negatively impact both the teacher supply and teaching quality. Some researchers report that $30 \%$ of new teachers leave the profession within their first five years of teaching (Ingersoll \& Merril, 2010; NCTAF, 2010) while others suggest higher rates between 40\% and 50\% (Grissmer \& Kirby, 1987, 1992, 1997; Ingersoll, 2003). Though not all estimates are equal, the fact that about one in three new teachers leave the profession is evidence that the stability and sustainability of the

\footnotetext{
${ }^{1}$ Corresponding Author. Department of Mathematics Mail Stop 3257, Texas A\&M University, College Station, TX 77843. E-mail: jwhitfld@tamu.edu
}

Whitfield, G. J., Waxman, H., \& Scott, T. (2016). Comparing Robert Noyce Scholars and Non-Robert Noyce Scholars perceptions of teaching. Journal of Research in STEM Education, 2(2), 90-105 
teacher workforce is at risk.

The severity of the teacher shortage problem varies among grade levels, disciplines, and geographic areas. A teacher shortage area is a grade and discipline specific to a geographic area in which the U.S. Secretary of Education determines there is an inadequate supply of teachers (U.S. Department of Education, 2014). Bilingual education, foreign language, mathematics, science, and special education are some of the examples of teacher shortage areas. The continual lack of effective teachers in these teacher shortage areas has negatively impacted the quality of instruction and has created a cycle of ineffective teaching in classrooms that has numerous adverse implications (Darling-Hammond, 2007). This problem is even more acute in schools that serve low-income students or schools that serve predominantly Black or Hispanic students where there are high percentages of non-certified teachers (Carroll, 2007; United States Department of Education, 2015). Focusing on recruiting and retaining high quality, effective teachers in low-income schools and in teacher shortage areas has gained momentum in the national spotlight and is now at the forefront of many political initiatives.

The Robert Noyce Teacher Scholarship Program (TSP), funded by the National Science Foundation (NSF), is one example of a government initiative that was enacted to address the critical need of teachers in high-need schools or districts, specifically in the content areas of science, technology, engineering, and mathematics (STEM). This scholarship program encourages talented STEM students to pursue teaching careers in mathematics and science by providing institutions of higher education (IHE) funding to recruit "individuals with strong STEM backgrounds who might otherwise not have considered a career in K-12 teaching" (NSF, 2012, p. 7). Begun by an Act of Congress in 2002, the Robert Noyce TSP was reauthorized under the America COMPETES Act in 2007 and the American COMPETES Reauthorization Act of 2010. The program was designed to increase the number of STEM teachers with strong STEM content knowledge to teach in highneed school districts. STEM students who are awarded the scholarship receive substantial funds - sometimes as much as $\$ 20,000$ - and as part of their scholarship they are required to complete one year of teaching in a high-need public school district for each semester of financial support. The Robert Noyce TSP has awarded scholarships to a sizable number of high achieving STEM students throughout the United States, but the actual impact the program has had on recruiting and retaining high-quality teachers in high-need schools is unclear.

Uncovering the role that scholarships play in influencing students to enter the teaching profession in high-need schools is a complex task. Many factors, both intrinsic and extrinsic, contribute to the decisions students make to enter the teaching profession. Some scholarship recipients cite reasons like wanting to change society and children, teaching subject matter they are passionate about, and being a positive role model for children (Bull, Marks, \& Salyer, 1994; Henry, Bastian, \& Smith, 2012) as reasons for entering the teaching profession. Other scholars may have a tainted portrayal of low-income urban areas and, as such, have more of a missionary perspective that drives them to enter the teaching profession and "save" the underprivileged students (Irizarry, 2009). This general desire to help others is a common characteristic found in effective teachers (Stronge, 2007). Internal factors, such as the ones mentioned above, contribute to the scholarship recipients' decisions to enter teaching, but there are also external reasons such as teaching scholarships.

Scholarships that are designed to combat the teacher shortage problem and increase the number of teachers in high-need fields generally include some financial incentive. The extent to which the financial incentive effects the scholar's decision to become a teacher, or teach in low-income schools, is difficult to measure. However, one factor that was found to impact scholars' decisions to accept the funding was the amount awarded. Scholars' were influenced more when the financial incentive covered a higher proportion of their tuition (Darling-Hammond, 2007; Henry et al., 2012; Liou \& Lawrenz, 2011). For the Noyce Teaching Scholarship specifically, some research has shown that the financial incentive did not influence the scholars' decisions to enter the teaching profession; many of the Noyce Scholars would have entered the teaching profession regardless of the financial incentive (Bull et al., 1994; Liou, Desjardins, \& Lawrenz, 2010). Liou \& Lawrenz 
2011) found, however, that Noyce Scholars who originally did not consider a career in teaching, the financial incentive did have a larger impact on their decision to enter the teaching profession. Competitive scholarships appear to attract individuals with significantly higher academic credentials and higher levels of human capital into teaching, but unless the scholarship programs require recipients to work in high-need schools, they tend to teach in schools and classrooms with more high-achieving and low-poverty students (Henry et al., 2012). The financial incentive offered by the Noyce Scholarship had the most influence on recruiting teachers to highneed schools and completing their certification program, but less of an influence on staying in a high-needs schools for long periods of time (Liou, Desjardins, \& Lawrenz, 2010; Liou, Kirchhoff, \& Lawrenz, 2010; Liou \& Lawrenz, 2011). Using scholarships as mechanisms to recruit teachers into high need fields has its own set of challenges. Thus, it is necessary to continue to study these challenges and modify them to meet the needs of the forecasted teacher market.

Though some research exists on factors that influence Noyce Scholars' decision to enter the teaching profession and how the financial incentive of the scholarship impacted their decision to teach, little research has been conducted on characteristics unique to Noyce Scholars. Comparing the perceptions of Noyce Scholars on various aspects of teaching and the teaching profession with a similar group of teachers that did not receive the Noyce scholarship can possibly shed some light on differences between Noyce Scholars and non-Noyce Scholars. The research questions guiding this study are:

1. How do the Noyce Scholars perceptions of teaching and of the teaching profession differ from the perceptions of a group of non-Noyce Scholars who were certified through the same teacher preparation program?

2. How do Noyce Scholars decisions about becoming a teacher, about staying in the teaching profession, and about plans for graduate education differ from a group of non-Noyce Scholars who were certified through the same teacher preparation program?

\section{Methodology}

Design

For this study, we used a quasi-experimental design and applied stratified matched sampling to compare the characteristics and perceptions of participants who received a Noyce scholarship to those participants who did not. Targeted participants were students who received their secondary mathematics or science teaching certification from a university in the southwestern region of the United States and who all participated in the same secondary undergraduate teacher preparation program. The data for this study were generated from one survey that was administered electronically to 61 participants during the summer of 2015.

\section{Participants}

The pool of participants for this study was comprised of teachers who were all certified from the same teacher preparation program during 2002-2014. The teacher preparation program from which the participants graduated was a secondary, undergraduate program at a large, research university located in the South Central region of Texas. The program certifies students who are working toward a bachelor's degree in mathematics or science to be teachers in Texas secondary schools. Each student in the program takes at least 18 hours of education courses, observes in secondary schools for at least 120 hours, and completes either a 12-week student teaching experience or a one-year internship. All participants in this study received their initial teaching certification for either grades 7 or 8 to 12 .

From 2002-2007, and again from 2009-2014, the preparation program received two Robert Noyce Teaching Scholarship Grants providing funds to award high achieving students a scholarship to help fund their 
education. Each student was a mathematics or science major with at least a 3.0 average. At the beginning of each academic semester, a selection committee was appointed to review the applications and select a set of Noyce Scholars. Throughout the 10 years of funding, 71 students were selected as Noyce Scholars.

The Noyce Scholars received $\$ 5,000$ each semester for one to four semesters while agreeing to teach in a high-need school district for one year per each semester funded. If the agreement was not fulfilled, students had to pay back the money awarded in scholarship funds as an interest-bearing loan.

At the time of this study, 61 of the 71 Noyce Scholars were employed in the education profession and eligible to participate in the study. Of the 10 ineligible, one was in graduate school, six no longer had valid teaching certificates, one was teaching out of the state, and no contact information was found for the remaining two. Email messages were sent to all 61 eligible scholars inviting them to participate with a stipend of $\$ 675$. Fifteen did not respond (of those 6 had no functional email address), 19 declined to participate in the study, and 29 agreed to participate in the study.

The selected control group (referred to as non-Noyce Scholars) was comprised of teachers who were certified through the same teacher preparation program during 2002-2014, but did not receive a Noyce Scholarship. An email message was sent describing the terms of the study with a stipend of $\$ 675$. Three rounds of email messages were sent to the 178 eligible teachers for the control group and 130 did not respond (of those 9 had no functional email address), 9 declined to participate in the study, and 39 agreed to participate in the study (22\% response rate).

The 39 non-Noyce Scholars who agreed to participate in the study were stratified on two items-school locale code and years of experience in the education profession-and matched to the 29 selected Noyce Scholars. The school locale code (National Center for Educational Statistics [NCES], 2006) classifies schools based on its proximity to an urbanized area. The number of years of experience were examined and matched, as close as possible, to the school locale code and number of years of experience of the Noyce Scholars. This process resulted in the omission of seven non-Noyce Scholars and created a sample size of 29 (Noyce Scholars) and 32 (non-Noyce Scholars). This was intentional to account for any attrition that could occur throughout the three years of the larger, longitudinal study. Summaries of the demographics and employment characteristics of the participants are shown in Table 1.

Table 1.

Demographics and Employment Characteristics of Study Participants

\begin{tabular}{lccc}
\hline \multicolumn{1}{c}{ Characteristic } & Noyce & Non-Noyce & Total \\
\hline Gender & & & \\
$\quad$ Female & 19 & 26 & 45 \\
Male & 10 & 6 & 16 \\
Ethnicity & & & \\
$\quad$ White, Non-Hispanic & 26 & 28 & 54 \\
Black, Non-Hispanic & 1 & 0 & 1 \\
Hispanic & 1 & 2 & 3 \\
Asian or Pacific Islander & 1 & 1 & 2 \\
Other & 0 & 1 & 1 \\
School Locale & & & \\
City: Large/Midsize/Small & $4 / 2 / 2$ & $6 / 2 / 4$ & $10 / 4 / 6$ \\
Rural: Fringe/Distant & $6 / 0$ & $3 / 3$ & $9 / 4$ \\
Suburb: Large & 10 & 8 & 18 \\
Town: Distant/Fringe/Remote & $0 / 0 / 3$ & $2 / 2 / 0$ & $2 / 2 / 3$
\end{tabular}




\begin{tabular}{lccc} 
2014-2015 Job Title & 5 & 1 & 6 \\
School Administrator & 5 & 1 & 1 \\
District Level Administrator & 20 & 27 & 47 \\
Classroom Teacher & 4 & 3 & 7 \\
Other & & & \\
Number of Years of Experience & 2 & 1 & 3 \\
0 & 10 & 14 & 24 \\
$1-3$ & 8 & 10 & 18 \\
$4-5$ & 11 & 8 & 19 \\
$>5$ & & & \\
\hline
\end{tabular}

\section{Instrumentation}

The Summer 2015 survey was adapted from two other surveys; the Schools and Staffing Survey (SASS) created by the National Center for Educational Statistics (NCES, 2012) and the Noyce Scholar Survey developed at the University of Minnesota for the Noyce Evaluation Report (University of Minnesota, 2012). Questions were selected from these two surveys because both survey instruments had been previously administered and were found to be reliable and valid (NCES, 2012; Liou \& Lawrenz, 2009). Additionally, using questions adapted from these surveys allows for comparison of the results from this study to other studies.

The Summer 2015 survey contained 70 items that were classified in into nine sections: Personal Information (PI), Employment Information (EI), Decisions on Becoming a STEM Teacher (DBST), Mentoring and Induction Experiences (MIE), Impressions of Teaching and Current Job (ITCJ), Plans for Graduate Education (PGE), Teacher Preparation (TP), School Climate and Teacher Attitudes (SCTA), and the Noyce Scholarship (NS).

The questions on the survey had a variety of answer types: categorical scales, ordinal scales, and openended. Most of the ordinal scale questions had multi-part statements where participants ranked the statements on four- or five- point Likert scales.

\section{Procedures}

Each participant completed the survey. Questions from the categories of PI, EI, MIE, and NS were not used because the categories did not align with the research questions guiding this study. Additionally, because of the similarity of the questions in the categories ITSC and SCTA, ITSC questions were merged into SCTA creating four categories to be analyzed: DBST, PGE, TP, and SCTA

Each category contained either ordinal or nominal scales. DBST and PGE each contained two nominal scale questions; TP contained two ordinal scale and one nominal scale question; and SCTA contained 10 ordinal scale and three nominal scale questions, giving a total of eight nominal scale and 12 ordinal scale questions. These ordinal scales each had multiple statements that participants rated on 4- or 5-point Likert-type scales ranging from "Strongly Agree" to "Strongly Disagree".

For the eight questions with nominal scales, either the Mann-Whitney $U$ or the Chi-Square test was used to determine any significant differences between participants who received a Noyce scholarship and those who did not. For the 12 ordinal scale questions, an Exploratory Factor Analysis (EFA) was conducted to determine the factor structure of the statements within each question. For seven of the 12 ordinal scale questions, the individual EFAs identified that all statements within the question loaded on a single factor that accounted for between 44 to $70 \%$ of the variance for each factor. The Cronbach's Alpha for each of the factors was greater than $0.70(\alpha>0.70)$. For each of these seven latent variables, the following scales were named: Performance of School Leadership, Problems in Schools, Perceptions of Actual Control in the Classroom, Teacher Influence Over School Policy, Perceptions of Preparedness for 1st Year of Teaching, Opportunities 
within Teacher Certification Program, and Perceptions of Formal Evaluations. Table 2 shows the Cronbach's alpha, the eigenvalue, and the percent variance explained by each of the seven latent variables.

For the remaining five questions that did not load on a single factor with $\alpha>0.70$, further analysis was required. Four had $\alpha<0.70$ and the fifth question loaded on multiple factors, but did not have meaningful groupings. Thus, a reliability analysis was conducted to determine if the alpha value would increase if some statements within each question were omitted. For two, it was determined that the alpha value would increase and exceed 0.70 if some of the statements were omitted. Thus this statement was omitted to increase $a$ to 0.726 and for the other question, two statements were omitted to increase $\alpha$ to 0.748 . Two latent variables were created for these two questions; Perceptions of State Assessments and Job Satisfaction and Enthusiasm. Table 2 shows the Cronbach's alpha, eigenvalue, and the percent variance explained by each of these two latent variables.

Table 2.

Cronbach's Alpha, Eigenvalues, and Percent Variance for Seven Latent Variables.

\begin{tabular}{|c|c|c|c|c|}
\hline Latent Variable & Category & $\begin{array}{c}\text { Cronbach's } \\
\text { Alpha }\end{array}$ & Eigenvalue & $\begin{array}{c}\% \text { variance } \\
\text { explained }\end{array}$ \\
\hline Performance of School Leadership & SCTA & 0.91 & 4.913 & 61.414 \\
\hline Problems in Schools & SCTA & 0.905 & 5.472 & 54.718 \\
\hline Perceptions of Actual Control in the Classroom & SCTA & 0.776 & 2.986 & 49.768 \\
\hline Teacher Influence Over School Policy & SCTA & 0.778 & 3.112 & 44.462 \\
\hline Perceptions of Preparedness for $1^{\text {st }}$ Year of Teaching & TP & 0.878 & 4.409 & 55.118 \\
\hline Opportunities within Teacher Certification Program & $\mathrm{TP}$ & 0.823 & 2.673 & 66.814 \\
\hline Perceptions of Formal Evaluations & SCTA & 0.768 & 2.09 & 69.665 \\
\hline Perceptions of State Assessments ${ }^{\star}$ & SCTA & 0.726 & 2.17 & 45.783 \\
\hline Job Satisfaction and Enthusiasm ${ }^{*}$ & SCTA & 0.748 & 2.56 & 51.296 \\
\hline
\end{tabular}

* one statement removed ** two statements removed

For the third of the four questions that underwent the additional reliability analysis, the alpha value still did not exceed 0.70 when the statements were omitted. For this question, an alpha value of 0.662 was deemed acceptable and a scale titled School Environment was created. The School Environment scale had an eigenvalue of 1.999 and this variable explained $49.974 \%$ of the variance. The alpha value for the fourth question that underwent additional reliability analysis would not increase to an acceptable alpha level $(\alpha=0.383)$, hence this question was analyzed on a statement-by-statement basis with a Mann-Whitney $U$ test.

For the one ordinal scale question that loaded on multiple factors but did not have meaningful groupings, further reliability analysis was conducted, but it continued to fail to have meaningful groupings where all alpha values exceeded 0.70 . The first EFA on this question revealed five factors, but none of the statements within the factors could be labeled with a meaningful title and $\alpha>0.70$ for some of the factors by $\alpha<0.70$ for other factors. Thus, additional EFAs were conducted that forced the statements to load on four, three, two, and one factor. For all of these four EFAs, reliability and creating meaningful groupings continued to be a problem resulting in this 
question being analyzed on a statement-by-statement basis with a Mann-Whitney $\mathrm{U}$ test.

After all EFAs and additional analyses were conducted, it was determined that of the 12 ordinal scale questions, 10 loaded on individual factors and two did not load sufficiently on any factors. As such, ten latent variables were created and statement-by-statement analyses were conducted on the two questions that failed the EFA. The 10 latent variables and the two questions analyzed on a statement-by-statement basis did not meet the normal distribution assumption and equal variance requirement for parametric tests, so Mann-Whitney $U$ tests were conducted throughout the study to determine any significant differences between participants who received a Noyce scholarship and those who did not. For the latent variables, factor scores were calculated and used in the Mann-Whitney $\mathrm{U}$ tests.

\section{Results}

The responses from the survey were analyzed to help determine any statistically significant differences between two independent groups of participants across four categories of the survey. The four categories were: Decisions on Becoming a STEM Teacher (DBST), Plans for Graduate Education (PGE), Teacher Preparation (TP), and School Climate and Teacher Attitudes (SCTA). Some questions within categories were analyzed on a statement-by-statement basis and others had latent variables created via an Exploratory Factor Analysis. For the latent variables, corresponding factor scores were calculated and Mann-Whitney U tests were used to determine any significant differences between the groups on both the latent variables and the statement-bystatement analysis.

\section{Decisions on Becoming a STEM Teacher (DBST)}

The DBST category contained two nominal scale questions. The first question was "Did any of the following help you decide to become a STEM teacher?". A list of nine statements followed this question and participants responded to each statement with "yes" or "no". A Mann-Whitney U test produced statistically significant difference between the groups on two of the nine statements. For the first significant statement, "I like the flexibility and/or autonomy of STEM teaching.", results of the Mann-Whitney U test $(\mathrm{p}=0.011)$ indicated that non-Noyce participants were influenced more by the flexibility and/or autonomy of STEM teaching $(\mathrm{M}=0.88, \mathrm{SD}=0.336)$ than the Noyce participants $(\mathrm{M}=0.59, \mathrm{SD}=0.501)$. Glass' effect size value $(\Delta$ $=0.863$ ) suggested a high practical significance.

The second significant difference found in the first question concerned the statement "I feel that a teaching career is/will be conducive to my family life". Results of the Mann-Whitney U test $(p=0.005)$ indicated that non-Noyce participants were influenced more by a teaching career being conducive to family life $(\mathrm{M}=$ $0.88, \mathrm{SD}=0.336)$ than Noyce participants $(\mathrm{M}=0.55, \mathrm{SD}=0.506)$. Glass' effect size value $(\Delta=0.982)$ suggested a high practical significance. Table 3 shows the descriptive statistics and results of the Mann-Whitney $U$ test on all nine statements.

The second question in the DBST category that produced a statistically significant difference $(\mathrm{p}=$ $0.033)$ between non-Noyce $(\mathrm{M}=1.69, \mathrm{SD}=0.471)$ and Noyce participants $(\mathrm{M}=1.41, \mathrm{SD}=0.501)$ was "At what point in your life did you decide to become a STEM teacher?". For this question, participants chose one of the following three responses: Childhood/adolescence (age 18 or before), Early adulthood (age 19-22), or Adulthood (age 23 or older). 
Table 3.

Descriptive Statistics and Mann-Whitney U Test Results for the Question "Did any of the following help you decide to become a STEM teacher?".

\begin{tabular}{|c|c|c|c|c|c|c|}
\hline \multirow[t]{2}{*}{ Question } & \multicolumn{2}{|c|}{ Noyce } & \multicolumn{2}{|c|}{ Non-Noyce } & \multirow{2}{*}{$\begin{array}{c}\text { Mean } \\
\text { Diff }\end{array}$} & \multirow[b]{2}{*}{$\mathrm{M}-\mathrm{W} \mathrm{U}$} \\
\hline & Mean & $S D$ & Mean & $S D$ & & \\
\hline I like sharing my subject with others. & 0.93 & 0.258 & 0.94 & 0.246 & -0.01 & $p=.92$ \\
\hline I like working with young people. & 1.03 & 0.186 & 1.03 & 0.177 & 0 & $p=.944$ \\
\hline I like having summers off. & 0.76 & 0.435 & 0.75 & 0.44 & 0.01 & $p=.938$ \\
\hline $\begin{array}{l}\text { I like the flexibility and/or autonomy of STEM } \\
\text { teaching. }\end{array}$ & 0.59 & 0.501 & 0.87 & 0.336 & -0.28 & $p=.011^{\star}$ \\
\hline $\begin{array}{l}\text { I feel that a teaching career is/will be conducive to } \\
\text { my family life. }\end{array}$ & 0.55 & 0.506 & 0.87 & 0.336 & -0.32 & $p=.005^{\star}$ \\
\hline I feel that I have a talent for teaching STEM. & 0.9 & 0.31 & 0.87 & 0.336 & 0.03 & $p=.794$ \\
\hline $\begin{array}{l}\text { I feel this career allows me to 'make a difference' in } \\
\text { the world. }\end{array}$ & 0.97 & 0.186 & 0.97 & 0.177 & 0 & $p=.944$ \\
\hline I have family members that are/were teachers. & 0.55 & 0.506 & 0.62 & 0.492 & -0.07 & $p=.564$ \\
\hline $\begin{array}{l}\text { Other people encouraged me to become a STEM } \\
\text { teacher. }\end{array}$ & 0.38 & 0.494 & 0.47 & 0.507 & -0.09 & $p=.484$ \\
\hline
\end{tabular}

For the analysis, Childhood/adolescence was coded as "1", Early adulthood as "2", and Adulthood and " 3 ". The frequency counts indicate that significantly more Noyce participants decided to become a STEM teacher at the age of $18(\mathrm{n}=17)$ than non-Noyce $(\mathrm{n}=12)$. Additionally, significantly more non-Noyce participants decided to become a STEM teacher between the ages of 19 and $22(n=22)$ than Noyce $(n=10)$. Glass' effect size value $(\Delta=0.594)$ suggests a moderate practical significance.

\section{Plans for Graduate Education (PGE)}

The PGE category contained two dichotomous (yes or no), nominal scale questions. For the first, "Since graduating from the university have you taken any graduate level classes?", a chi-square test indicated a statistically significant difference $\chi^{\wedge} 2(1)=4.601, \mathrm{p}<0.05$ between groups indicating that significantly more Noyce participants (55\%) took some graduate level classes since graduating from the university than nonNoyce (28\%). For the second question, "Since graduating from the university have you received any advanced degrees?", a chi-square test indicated a statistically significant difference $\chi^{\wedge} 2(1)=4.824, p<0.05$ between groups indicating that significantly more Noyce participants (45\%) received advanced degrees since graduating from the university than non-Noyce (19\%).

\section{Teacher Preparation (TP)}

The TP category contained one nominal scale question that contained multiple dichotomous statements and two latent variables (formed in the EFA). The dichotomous statements were analyzed for differences between groups on a statement-by-statement basis. The two latent variables in TP were: (a) Opportunities within Teacher Certification Program and (b) Preparedness for 1st Year of Teaching. 
The nominal scale question, "Which of these were part of your experience in your teacher certification program?", was analyzed on a statement-by-statement basis with participants responding with "yes" or "no" to a list of 14 statements. A Mann-Whitney $U$ test indicated a statistically significant difference between the groups on only one statement - "Opportunities to interact with children from different cultures" $(\mathrm{p}=0.043)$ indicating that Noyce participants had significantly more opportunity to interact with children from different cultures $(\mathrm{M}$ $=1.34, \mathrm{SD}=0.484)$ than the non-Noyce participants $(\mathrm{M}=1.12, \mathrm{SD}=0.336)$. Glass' effect size value $(\Delta=0.655)$ suggested a moderately high practical significance. The descriptive statistics and results of the Mann-Whitney $\mathrm{U}$ test for each statement within this question are provided in Appendix A.

The two latent variables for the TP category were Opportunities within Teacher Certification Program $(M=0.004, S D=0.922)$ and Preparedness for 1st Year of Teaching $(M=-0.176, S D=1.01)$. A Mann-Whitney $\mathrm{U}$ test found no statistically significant differences between the two groups. The Opportunities within Teacher Certification latent variable had four statements that participants rated on a 5-point scale. The statements related to the question "In your teacher certification program, how much opportunity did you have to do the following" with 5 representing "Extensive Opportunity" and 1 represented "none". The means from each group ranged from 2.28 to 3.13. The Preparedness for 1st Year of Teaching had eight statements that participants rated on a 4-point scale. The statements referred to the prompt "In your first year of teaching, how well prepared were you to..." and the ratings ranged from 1 (not at all prepared) to 4 (very well prepared). The means from each group ranged from 2.14 to 3 with the exception of the statement "Teach your subject matter". For this statement, Noyce Scholars had a slightly lower means $(M=3.31)$ than the non-Noyce Scholars $(M=3.53)$.

\section{School Climate and Teacher Attitudes (SCTA)}

The SCTA category contained 13 questions ( 3 were categorical and 10 were ordinal). The three categorical questions were analyzed on a statement-by-statement basis for differences between groups. The results of the EFA indicated that two of the 10 ordinal questions needed to be analyzed as individual questions for differences between groups. Thus, this category contained five statement-by-statement analyses. Latent variables were created for the remaining eight ordinal questions and their corresponding factor scores were analyzed for differences among groups.

The first of the three categorical questions were "How long do you plan to remain in your current position?". Participants chose from eight statements (as long as I am able, until I am eligible for retirement benefits from this job, until I am eligible for Social Security benefits, until a specific life event occurs (e.g., parenthood, marriage), until a more desirable job opportunity comes along, definitely plan to leave as soon as I can, undecided at this time, other) and results of a Mann-Whitney U test indicated no statistically significant difference among groups. Table 4 shows the percentage of Noyce and non-Noyce scholars that selected each statement. Those participants that selected "other" reported the following statements when asked to specify: one more year, as long as it is a good position for my family, for several years before moving into administration, until I reach retirement age and then I would like to work in academia teaching others how to teach, until I become a professor, and I am working on acquiring a principal position in the coming years.

Table 4.

Percentage of Each Group's Responses to Question “How long do you plan to remain in your current position?”.

\begin{tabular}{lcc}
\hline \multicolumn{1}{c}{ Statement } & Noyce & Non-Noyce \\
\hline As long as I am able. & $41 \%$ & $56 \%$ \\
Until I am eligible for retirement benefits from this job. & 0 & 0 \\
Until I am eligible for retirement benefits from a previous job. & 0 & 0 \\
Until I am eligible for Social Security benefits. & 0 & 0 \\
Until a specific life event occurs (e.g., parenthood, marriage). & $4 \%$ & $9 \%$ \\
Until a more desirable job opportunity comes along. & $21 \%$ & $3 \%$
\end{tabular}


Definitely plan to leave as soon as I can.

Undecided at this time.

Other

$\begin{array}{cc}0 & 0 \\ 24 \% & 22 \% \\ 10 \% & 10 \%\end{array}$

The second categorical question was "If you could go back to your college days and start over again, would you choose to teach again or not?". Participants ranked their responses on a 5-point scale. The percentages of responses to this question are show in Table 5. Results of the Mann-Whitney U test indicated no statistically significant difference among groups for any of these responses.

Table 5.

Percentage of Responses to Question "If you could go back to your college days and start over again, would you choose to teach again or not?".

\begin{tabular}{lccccccc}
\hline & $\begin{array}{c}\text { Certainly } \\
\text { would (5) }\end{array}$ & $\begin{array}{c}\text { Probably } \\
\text { would (4) }\end{array}$ & $\begin{array}{c}\text { Chances are } \\
\text { about even } \\
(3)\end{array}$ & $\begin{array}{c}\text { Probably } \\
\text { would not } \\
(2)\end{array}$ & $\begin{array}{c}\text { Certainly would } \\
\text { not (1) }\end{array}$ & Mean & $S D$ \\
\hline Noyce & $73 \%$ & $17 \%$ & $10 \%$ & 0 & 0 & 4.62 & 0.677 \\
non-Noyce & $60 \%$ & $25 \%$ & $12 \%$ & $3 \%$ & 0 & 4.41 & 0.837 \\
\hline
\end{tabular}

The third categorical question was "Which of the following describes your employment during the 2014-2015 school year?". Percentages and descriptive statistics for this question are show in Table 6. Results of the Mann-Whitney $\mathrm{U}$ test $(\mathrm{p}=0.016)$ indicated that significantly more Noyce participants were employed in a high-needs schools $(\mathrm{M}=1.28, \mathrm{SD}=0.591)$ than the non-Noyce participants $(\mathrm{M}=1.46, \mathrm{SD}=0.647)$. The participants that chose the response "other" reported that they were not sure of their school's high-need status.

Table 6.

Percentages and Descriptive Statistics for the Question "Which of the following describes your employment during the 2014-2015 school year?".

\begin{tabular}{lccccc}
\hline & $\begin{array}{c}\text { I worked in high } \\
\text { needs (3) }\end{array}$ & $\begin{array}{c}\text { I worked in another type } \\
\text { of school (2) }\end{array}$ & Other (1) & Mean & $S D$ \\
\hline Noyce & $79 \%$ & $14 \%$ & $7 \%$ & 1.28 & 0.591 \\
non-Noyce & $47 \%$ & $44 \%$ & $9 \%$ & 1.46 & 0.647 \\
\hline
\end{tabular}

In the SCTA category there were two ordinal questions that did not reliably load on a factor. The first question was "How much do you agree or disagree with each of the following statements about teaching?". Participants ranked the five statements relating to satisfaction with their current job on a 5-point scale from "Strongly Agree" to "Strongly Disagree". A Mann-Whitney U test was conducted on a statement-by-statement basis but no statistically significant results were found. Table 7 shows the descriptive statistics and results of the Mann-Whitney U test. 
Table 7.

Descriptive Statistics and Results of Mann-Whitney U test for Question "How much do you agree or disagree with each of the following statements about teaching?".

\begin{tabular}{|c|c|c|c|c|c|c|}
\hline \multirow{2}{*}{ Statements } & \multicolumn{2}{|c|}{ Noyce } & \multicolumn{2}{|c|}{ non-Noyce } & \multirow{2}{*}{$\begin{array}{l}\text { Diff. of } \\
\text { Means }\end{array}$} & \multirow[b]{2}{*}{$\mathrm{M}-\mathrm{W}-\mathrm{U}$} \\
\hline & Mean & $S D$ & Mean & $S D$ & & \\
\hline I am satisfied with my current job. & 4.41 & 0.628 & 4.22 & 0.941 & 4.31 & $p=.455$ \\
\hline I really dislike STEM teaching. & 1.1 & 0.557 & 1.41 & 0.712 & 1.26 & $p=.090$ \\
\hline $\begin{array}{l}\text { If I had to do it all over again, I would choose } \\
\text { the same teacher preparation program and/or } \\
\text { route into teaching. }\end{array}$ & 4.34 & 0.814 & 4.44 & 0.759 & 4.39 & $p=.657$ \\
\hline $\begin{array}{l}\text { If I had to do it all over again, in view of my } \\
\text { present knowledge, I would become a teacher. }\end{array}$ & 4.34 & 0.721 & 4.34 & 0.701 & 4.34 & $p=.961$ \\
\hline $\begin{array}{l}\text { I am likely to assume a leadership position } \\
\text { (e.g., lead teacher, depart. chair, official or } \\
\text { unofficial mentor) }\end{array}$ & 3.48 & 1.805 & 3.66 & 1.335 & 3.57 & $p=.816$ \\
\hline
\end{tabular}

The second question that did not reliably load on a factor was "To what extent do you agree or disagree with each of the following statements?". Participants ranked 18 statements relating to various aspects of school climate and teacher attitudes on a 4-point scale from "Strongly Agree" to "Strongly Disagree". A Mann-Whitney $\mathrm{U}$ test was conducted on a statement-by-statement basis but no statistically significant results were found. The descriptive statistics and results of the Mann-Whitney U test for this question are shown in Appendix B.

Finally, a Mann-Whitney $U$ test was conducted on the eight latent variables associated with this category. The eight latent variables were: Performance of School Leadership, Problems in Schools, Perceptions of Actual Control in the Classroom, Teacher Influence Over School Policy, Perceptions of Formal Evaluations, School Environment, Perceptions of State Assessments, and Job Satisfaction and Enthusiasm. A Mann-Whitney $\mathrm{U}$ test indicated no statistically significant differences between the groups on any of the eight latent variables. The Performance of School Leadership latent variable had eight statements that participants rated on a 5-point scale. The statements related to the question "How effectively do you feel the principal or school head performed each of the following at last year's school" and the ratings ranged from 1 (not at all effectively) to 5 (extremely effectively). The means of both groups ranged from 2.97 to 3.69.

The Problems in Schools latent variable had ten statements that participants rated on a 4-point scale. The statements related to the question "To what extent is each of the following a problem in this school?" with ratings from 1 (not a problem) to 4 (serious problem). The means of both groups ranged from 1.75 to 2.83 .

The Perceptions of Actual Control in the Classroom latent variable had six statements that participants rated on a 4-point scale. The statements related to the question "How much actual control do you have in your classroom at your last school over the following areas of your planning and teaching?". Ratings ranged from 1(no control) to 4 (a great deal of control). The means of both groups ranged from 2.5 to 3.77 .

The Teacher Influence Over School Policy latent variable had seven statements that participants rated on a 4-point scale. The statements related to the question "How much actual influence do you think teachers have over school policy at your last school in each of the following areas?". Ratings ranged from 1(no influence) to 4 (a great deal of influence). The means of both groups ranged from 1.66 to 2.48 with higher means of 2.59 (Noyce) and 3.22 (non-Noyce) for the one statement regarding establishing curriculum. 
The Perceptions of Formal Evaluations latent variable had three statements that participants rated on a 4-point scale. The statements related to the question "To what extent do you agree or disagree with each of the following statements about the formal evaluation of your work as a teacher last school year?". Ratings ranged from 1 (strongly disagree) to 4 (strongly agree). The means of both groups ranged from 2.94 to 3.67 .

The School Environment latent variable had four statements that participants rated on a 5-point scale. The statements related to the question "Please rate your school environment as high, medium, or low on the features listed below.. Ratings ranged from 1 (very low) to 5 (very high). The means of both groups ranged from 3.28 to 3.9 .

The Perceptions of State Assessments latent variable had five statements that participants rated on a 4-point scale. The statements related to the question "To what extent do you agree or disagree with each of the following statements about the state assessment program during the 2014-2015 school year?". Ratings ranged from 1 (strongly disagree) to 4 (strongly agree). The means of both groups ranged from 2.74 to 3.32 with the exception of one statement. The statement "I did not receive adequate support in preparing my students for the assessments." had means of 1.79 (Noyce) and 1.73 (non-Noyce).

The Job Satisfaction and Enthusiasm latent variable had seven statements that participants rated on a 4-point scale. The statements related to the question "To what extent do you agree or disagree with each of the following statements?". Ratings ranged from 1 (strongly disagree) to 4 (strongly agree). The means, each posed in a negative connotation, of both groups ranged from 1.47 to 2 . The means on the other two statements, each posed in a positive connotation, of both groups ranged from 2.97 to 3.28 .

\section{Discussion}

The impact that scholarships related to teaching have on recruiting and retaining high-quality teachers in high-need schools is unclear. This is also true of the Robert Noyce Teaching Scholarship. Some research exists on factors that influence Noyce Scholars' decision to enter the teaching profession and how the financial incentive of the scholarship impacted their decision to teach (Bull et al., 1994; Darling-Hammond, 2007; Liou, Desjardins, \& Lawrenz, 2010; Liou \& Lawrenz, 2011; Henry et al., 2012) but little research can be found on characteristics special to Noyce Scholars. If some profiling of the Noyce Scholar can be done, then universities can use the information during the recruiting and preparation phase to improve teaching and teacher preparation.

In this study, four categories were analyzed to investigate the perceptions and characteristics of Noyce Scholars about teaching and the teaching profession. The four categories were Decisions on Becoming a STEM Teacher (DBST), Plans for Graduate Education (PGE), Teacher Preparation (TP), and School Climate and Teacher Attitudes (SCTA). To aid in identifying any perceptions and characteristics unique to Noyce Scholars across these categories, data was compared to a group of non-Noyce Scholars who received their teacher training from the same teacher preparation program. Non-parametric inferential statistics used on the data indicated some significant differences between groups across three of the four categories.

In the DBST and PGE categories, the results indicate that differences between Noyce Scholars and nonNoyce Scholars do exist. The Noyce Scholars, in general, made decisions about their future plans at younger ages and for different reasons than the non-Noyce Scholars. Significantly more Noyce Scholars decided to become teachers before the age of 18 than non-Noyce Scholars and external factors like flexibility or autonomy of STEM teaching and conduciveness to family life seemed to be less of an influence on their decisions to teach. This suggests that during their high school years, Noyce Scholars are actively thinking about their future careers; they are early career deciders. Noyce Scholars may be giving more weight to reasons like "love of a subject" and "making a difference in the world" than reasons like "flexibility or autonomy of STEM teaching" and "conduciveness to family life" for deciding to be a teacher. Noyce Scholars appear to be less influenced 
during their college-aged years on making a career choice since many of them made the decision before 18 . Non-Noyce Scholars, on the other hand, seem to enter college undecided on a career choice and maybe more influenced by external factors when choosing a career. Thus, when recruiting teachers into the profession during the college years, external factors like "flexibility or autonomy of STEM teaching" and "conduciveness to family life" may be good aspects of the teaching profession to highlight to recruit college students into the teaching profession or have them consider teaching as a career.

Results in the PGE category also indicate that Noyce Scholars decide to invest in their graduate education at a higher rate than their non-Noyce counterparts. This could be due, in part, to the funds that the Noyce Scholars received as undergraduates or that Noyce Scholars were academically successful students. Receiving the scholarship funds as an undergraduate could have put the Noyce Scholars in a position where they had less student loan debt and thus, more willingness to invest money in graduate studies. This notion cannot be fully supported by the results of this study, but it is something that could be explored in future studies. Additionally, Noyce Scholars were required to have a 3.0 grade point average to be eligible for the scholarship. This prerequisite condition for the scholarship may play a role in the motivation for Noyce Scholars to seek more graduate education than the non-Noyce Scholars. Nonetheless, this supports the notion that Noyce Scholars make decisions about their future earlier than the non-Noyce Scholars.

Results in the TP category indicate that there are few differences between groups regarding the participants' perceptions of their preparedness for 1st year of teaching and the opportunities with the teacher preparation program. This is not surprising because all participants in the study were similarly trained. The opportunity to interact with children from difference cultures showed Noyce Scholars reporting more opportunity to interact with children from different cultures during their teacher preparation than non-Noyce Scholars. Again, this is not surprising because of the structure of the program. Noyce Scholars were required to tutor, mentor, or assist with groups of children that came from the lower socioeconomic sub-groupings.

Results in the SCTA category imply little difference between groups regarding the participants' perceptions on school climate and teacher attitudes. There was only one statistically significant difference between groups and that was in the type of school (high-needs or not) in which the participants were employed. This finding, however, is not surprising given that Noyce Scholars agreed to teach in a high-needs school district when they accept the Noyce Teaching Scholarship. Thus, this finding seems to be influenced by the requirements of the Noyce Scholarship program and is also in align with current research on scholarship programs; the financial incentive has the most influence on recruiting teachers to high-need schools.

Though there is little difference among groups in the SCTA category, the results of the analysis do indicate that the overall perception of the participants regarding school climate and teacher attitudes is fairly positive. Most of the participants expressed a desire to stay in the profession and also indicated they would choose to teach again given the opportunity to start their college days over. The lowest scores were in the Teacher Influence Over School Policy, indicating that participants had minor to moderate influence over school policy. Further research could investigate relationships between teachers' attitudes toward the profession and their perceived influence over school policy. Future studies could also try to include greater incentives for participating in the study in order to obtain a more representative sample.

\section{References}

Bull, K. S., Marks, S., \& Salyer, B. K. (1994). Future teacher scholarship programs for science education: Rationale for teaching in perceived high-need areas. Journal of Science Education and Technology, 3(1), 71-76.

Carroll, T. (2007). The high cost of teacher turnover. Washington, DC: National Commission on Teaching and America's Future.

Darling-Hammond, L. (2007). We need to invest in math and science teachers. Chronicle of Higher Education, 
54(17), B20. Retrieved from https://chronicle.com/article/We-Need-to-Invest-in-Math-and/14523.

Grissmer, D., \& Kirby, S. (1987). Teacher attrition: The uphill climb to staff the nation's schools. Santa Monica, CA: RAND. Retrieved from ERIC database. (ED291735)

Grissmer, D., \& Kirby, S. (1992). Patterns of attrition among Indiana teachers, 1965- 1987. Santa Monica, CA: RAND.

Grissmer, D., \& Kirby, S. (1997). Teacher turnover and teacher quality. Teachers College Record, 99, 45-56.

Henry, G. T., Bastian, K. C., \& Smith, A. A. (2012). Scholarships to recruit the "best and brightest" into teaching: Who is recruited, where do they teach, how effective are they, and how long do they stay? Educational Researcher, 41(3), 83-92.

Ingersoll, R. (2003). Is there really a teacher shortage? Philadelphia, PA: Consortium for Policy Research in Education, University of Pennsylvania. Retrieved from http://repository.upenn.edu/gse_pubs/133

Ingersoll, R., \& Merrill, L. (2010). Who's teaching our children? Educational Leadership, 67(8), 14-20.

Irizarry, J. G. (2009). Representin' drawing from hip-hop and urban youth culture to inform teacher education. Education and Urban Society, 41(4), 489-515.

Liou, P. Y., Desjardins, C. D., \& Lawrenz, F. (2010). Influence of scholarships on STEM teachers: Cluster analysis and characteristics. School Science and Mathematics, 110(3), 128-143.

Liou, P. Y., Kirchhoff, A., \& Lawrenz, F. (2010). Perceived effects of scholarships on STEM majors' commitment to teaching in high-need schools. Journal of Science Teacher Education, 21(4), 451-470.

Liou, P. Y., \& Lawrenz, F. (2009). University of Minnesota evaluation of the Robert Noyce Teacher Scholarship Program, final report section two: Factor analysis of the Evaluation questionnaire. Retreived from http:// www.cehd.umn.edu/EdPsych/NOYCE/Reports/default.html

Liou, P. Y., \& Lawrenz, F. (2011). Optimizing teacher preparation loan forgiveness programs: Variables related to perceived influence. Science Education, 95(1), 121-144.

National Center for Educational Statistics. (2006). Common Core of Data. Retrieved from https://nces.ed.gov/ ccd/rural_locales.asp

National Center for Educational Statistics. (2012). Teacher questionnaire schools and staffing survey 2011-2012 school year. Retrieved from https://nces.ed.gov/surveys/sass/pdf/1112/SASS4A.pdf

National Commission on Teaching and America's Future. (2010). Who will teach? Experience matters. Washington DC: National Commission on Teaching and America's Future. Retrieved from http://nctaf. org/wp-content/uploads/2012/01/NCTAF-Who-Will-Teach-Experience-Matters-2010-Report.pdf

National Science Foundation. (2012). Prepare, practice, partner: Innovative strategies from the Robert Noyce Teacher Scholarship Program Conferences. American Association for the Advancement of Science. Retrieved from http://nsfnoyce.org/files/2012/05/NoycePub_2012_web.pdf

Stronge, J. H. (2007). Qualities of effective teachers. Alexandria, VA: Association for Supervision and Curriculum Development.

University of Minnesota College of Education \& Human Development Resources for Recruitment and Retention of STEM Teachers. (2012). Instruments. Retrieved from http://www.cehd.umn.edu/EdPsych/ NOYCE/Instruments.html

United States Department of Education. (2015). The Condition of Education 2015. National Center for Education Statistics. Retrieved from http://nces.ed.gov/pubsearch.

United States Department of Education, Office of Postsecondary Education. (2014). Teacher shortage areas nationwide listing 1990-1991 through 2014-2015. Washington D.C: Retrieved from http://www2.ed.gov/ about/offices/list/ope/pol/tsa.doc. 


\section{Appendix A}

Descriptive Statistics and Results from Mann-Whitney U Test for the Question "Which of theses were part of your experience in your teacher certification program?".

\begin{tabular}{|c|c|c|c|c|c|c|}
\hline \multirow[t]{2}{*}{ Question } & \multicolumn{2}{|c|}{ Noyce } & \multicolumn{2}{|c|}{ Non-Noyce } & \multirow{2}{*}{$\begin{array}{c}\text { Mean } \\
\text { Diff }\end{array}$} & \multirow[b]{2}{*}{$\mathrm{M}-\mathrm{W} \mathrm{U}$} \\
\hline & Mean & $S D$ & Mean & $S D$ & & \\
\hline $\begin{array}{l}\text { Opportunities to interact with adults from different cul- } \\
\text { tures }\end{array}$ & 1.45 & 0.506 & 1.38 & 0.492 & 0.07 & 0.564 \\
\hline $\begin{array}{l}\text { Opportunities to interact with children from different } \\
\text { cultures }\end{array}$ & 1.34 & 0.484 & 1.12 & 0.336 & 0.22 & $0.043^{*}$ \\
\hline Education about different cultures & 1.28 & 0.455 & 1.16 & 0.369 & 0.12 & 0.259 \\
\hline $\begin{array}{l}\text { Class(es) in teaching methods specific to your subject area } \\
\text { (e.g., science or math) }\end{array}$ & 1.03 & 0.186 & 1.09 & 0.296 & -0.06 & 0.354 \\
\hline $\begin{array}{l}\text { Education about how to work in high needs schools spe- } \\
\text { cifically }\end{array}$ & 1.52 & 0.509 & 1.66 & 0.483 & -0.14 & 0.274 \\
\hline $\begin{array}{l}\text { Opportunities to observe/work at high needs schools (not } \\
\text { student teaching) }\end{array}$ & 1.21 & 0.412 & 1.25 & 0.44 & -0.04 & 0.692 \\
\hline Student teaching experience & 1.1 & 0.31 & 1.06 & 0.246 & 0.04 & 0.564 \\
\hline Student teaching experience in a high needs school & 1.52 & 0.509 & 1.66 & 0.483 & -0.14 & 0.274 \\
\hline $\begin{array}{l}\text { A guaranteed job (assuming successful completion of pro- } \\
\text { gram) at a participating school district }\end{array}$ & 1.83 & 0.384 & 1.84 & 0.369 & -0.01 & 0.866 \\
\hline $\begin{array}{l}\text { Mentoring experiences provided by your certification pro- } \\
\text { gram during your first year of teaching }\end{array}$ & 1.72 & 0.455 & 1.69 & 0.471 & 0.03 & 0.756 \\
\hline $\begin{array}{l}\text { Mentoring experiences provided by your district during } \\
\text { your first year of teaching }\end{array}$ & 1.24 & 0.435 & 1.16 & 0.369 & 0.08 & 0.407 \\
\hline $\begin{array}{l}\text { Mentoring experiences provided by your certification pro- } \\
\text { gram during your second year of teaching }\end{array}$ & 1.79 & 0.412 & 1.84 & 0.369 & -0.05 & 0.610 \\
\hline $\begin{array}{l}\text { Mentoring experiences provided by your district during } \\
\text { your second year of teaching }\end{array}$ & 1.76 & 0.435 & 1.72 & 0.457 & 0.04 & 0.726 \\
\hline $\begin{array}{l}\text { Continuing contact with participants in your teacher edu- } \\
\text { cation program }\end{array}$ & 1.72 & 0.455 & 1.53 & 0.507 & 0.19 & 0.124 \\
\hline
\end{tabular}




\section{Appendix B}

Descriptive Statistics and results of Mann-Whitney U test for question "To what extent do you agree or disagree with each of the following statements?".

\begin{tabular}{|c|c|c|c|c|c|c|}
\hline \multirow{2}{*}{ Statements } & \multicolumn{2}{|c|}{ Noyce } & \multicolumn{2}{|c|}{ Non-Noyce } & \multirow{2}{*}{$\begin{array}{l}\text { Mean } \\
\text { Diff. }\end{array}$} & \multirow[b]{2}{*}{$\mathrm{M}-\mathrm{W} \mathrm{U}$} \\
\hline & Mean & $S D$ & Mean & $S D$ & & \\
\hline $\begin{array}{l}\text { The school administration's behavior toward the staff is sup- } \\
\text { portive and encouraging. }\end{array}$ & 3.38 & 0.775 & 3.16 & 0.92 & 0.22 & 0.298 \\
\hline I am satisfied with my salary. & 2.93 & 0.842 & 2.78 & 0.941 & 0.15 & 0.525 \\
\hline $\begin{array}{l}\text { The level of student misbehavior in this school (such as- } \\
\text { noise, horseplay or fighting in the galls, cafeteria, or student } \\
\text { lounge) interferes with my teaching. }\end{array}$ & 2.10 & 1.145 & 1.78 & 0.906 & 0.32 & 0.348 \\
\hline $\begin{array}{l}\text { I receive a great deal of support from parents for the work I } \\
\text { do. }\end{array}$ & 2.55 & 0.870 & 2.62 & 1.008 & 0.22 & 0.690 \\
\hline $\begin{array}{l}\text { Necessary materials such as textbooks, supplies, and copy ma- } \\
\text { chines are available as needed by the staff. }\end{array}$ & 3.31 & 0.806 & 3.28 & 0.813 & 0.03 & 0.823 \\
\hline $\begin{array}{l}\text { Routine duties and paperwork interfere with my job of teach- } \\
\text { ing. }\end{array}$ & 2.72 & 0.96 & 2.44 & 1.014 & 0.28 & 0.324 \\
\hline $\begin{array}{l}\text { My principal enforces school rules for student con- } \\
\text { duct and backs me up when I need it. }\end{array}$ & 3.0 & 0.756 & 3.0 & 1.107 & 0 & 0.549 \\
\hline $\begin{array}{l}\text { Teachers in this school consistently enforce rules for student } \\
\text { behavior, even for students who are not in their classes. }\end{array}$ & 2.45 & 0.827 & 2.47 & 0.983 & -0.02 & 0.860 \\
\hline $\begin{array}{l}\text { Most of my colleagues share my beliefs and values about what } \\
\text { the central mission of the school should be. }\end{array}$ & 3.03 & 0.823 & 2.84 & 0.847 & 0.19 & 0.261 \\
\hline $\begin{array}{l}\text { The principal knows what kind of school he or she } \\
\text { wants and has communicated it to the staff. }\end{array}$ & 3.17 & 0.759 & 3.03 & 1.062 & 0.14 & 0.894 \\
\hline $\begin{array}{l}\text { There is a great deal of cooperative efforts among staff mem- } \\
\text { bers. }\end{array}$ & 3.21 & 0.62 & 3.13 & 0.942 & 0.08 & 0.911 \\
\hline $\begin{array}{l}\text { In this school, staff members are recognized for a job well } \\
\text { done. }\end{array}$ & 3.24 & 0.786 & 2.94 & 0.840 & 0.30 & 0.118 \\
\hline $\begin{array}{l}\text { I worry about the security of my job because of the } \\
\text { performance of my students or my school on state and/or } \\
\text { local tests. }\end{array}$ & 1.38 & 0.561 & 1.47 & 0.879 & -0.09 & 0.933 \\
\hline $\begin{array}{l}\text { State or district content standards have had a positive } \\
\text { influence on my satisfaction with teaching. }\end{array}$ & 1.93 & 1.033 & 2.16 & 1.051 & -0.23 & 0.441 \\
\hline $\begin{array}{l}\text { I am given the support I need to teach students with } \\
\text { special needs. }\end{array}$ & 2.66 & 1.111 & 2.59 & 1.103 & 0.07 & 0.712 \\
\hline $\begin{array}{l}\text { The amount of student tardiness and class cut- } \\
\text { ting in this school interferes with my teaching. }\end{array}$ & 2.17 & 1.037 & 2.03 & 1.092 & 0.14 & 0.804 \\
\hline $\begin{array}{l}\text { I am generally satisfied with being a teacher at this } \\
\text { school. }\end{array}$ & 3.45 & 0.910 & 3.37 & 0.871 & 0.08 & 0.561 \\
\hline $\begin{array}{l}\text { I make a conscious effort to coordinate the content of } \\
\text { my courses with that of other teachers. }\end{array}$ & 3.07 & 0.998 & 3.13 & 0.942 & -0.06 & 0.852 \\
\hline
\end{tabular}

